\title{
Study on switching principle of thyristor assisted arc extinguishing hybrid OLTC
}

\author{
Yu Yin ${ }^{1}$, Fei Gao ${ }^{1}$, Fei $\mathrm{Shi}^{2}$, Peng-Fei Jia ${ }^{1, *}$, Ben-Ping Ding ${ }^{2}$, Lu-Ning $\mathrm{Hao}^{2}$, Lei Zhang ${ }^{2}$ and Chao Liu ${ }^{3}$ \\ ${ }^{1}$ China Electric Power Research Institute, High Voltage Research Institute, 15 Xiaoying East Road, Qinghe, Haidian District, Beijing, \\ China \\ ${ }^{2}$ Shandong taikai Electric Power Equipment Co., Taikai Industrial Park, South District, high tech Development Zone, Tai'an City, China \\ ${ }^{3}$ Electric Power Research Institute, Xizang Electric Power Co., Ltd, 17 Sela Road, Lasa, China
}

\begin{abstract}
Thyristor assisted arc extinguishing hybrid on load tap changer has the advantages of both mechanical switch and thyristor switch. It has strong ability to withstand overload, over-current and overvoltage, high reliability, small maintenance workload and frequent voltage regulation operation. It is a promising on load tap changer of transformer. This paper introduces the principle of passive trigger of thyristor module, gives the switching principle and process of thyristor assisted arc extinguishing hybrid on load tap changer, and analyses the characteristics of hybrid on load tap changer.
\end{abstract}

\section{Introduction}

The thyristor assisted arc extinguishing hybrid on load tap changer retains the tap selector and switching switch of the mechanical on load tap changer, and the reverse parallel thyristor is added in the transition circuit to assist the mechanical contact to complete the switching ${ }^{[1]}$. After switching, the reverse parallel thyristor exits the current carrying circuit, and the current carrying is completed by the mechanical contact. In order to realize the passive triggering of thyristor, this paper proposes an improved switching principle of thyristor assisted arc extinguishing hybrid on load tap changer, which combines the existing $\mathrm{km}$ type tap changer and hybrid on load tap changer switching principle ${ }^{[2]}$. This scheme adopts three groups of basic thyristor circuits, which can truly realize the passive trigger and exit mechanism of thyristor, and make full use of the existing $\mathrm{km}$ type on load tap changer Other parts of the switch have the advantages of low cost and good expansibility.

\section{Passive trigger principle of thyristor}

Thyristor is a high-power semiconductor device with three PN junction and four-layer structure ${ }^{[3]}$. It can work under high voltage and high current conditions. It is widely used in controlled rectifier, $\mathrm{AC}$ voltage regulation, contactless electronic switch, inverter and frequency conversion and other electronic circuits ${ }^{[4]}$. As shown in Figure 1, the reverse parallel thyristor module is composed of two unidirectional thyristors in inverse parallel connection, $\mathrm{a}$ is the anode, $\mathrm{K}$ is the cathode, $\mathrm{G}$ is the gate, in which G1 and G2 are the respective gates of the two thyristors, which are respectively connected with trigger branches. 2 and 3 relate to 1 to form two ports. In the AC circuit, the voltage is applied to the two ports. At any time, one thyristor bears the forward voltage drop and the other thyristor bears the reverse voltage drop. Therefore, if the same trigger signal is applied to the thyristor module at the same time, there will always be one thyristor that is triggered to conduct the current.

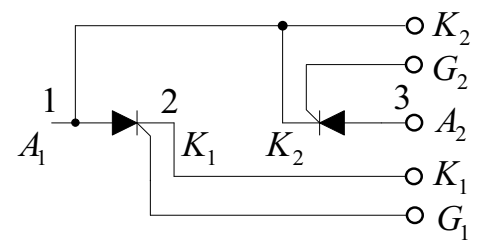

Fig. 1. Reverse parallel thyristor module

The principle of passive trigger of thyristor auxiliary mechanical contact action is shown in Figure 2. A pair of reverse parallel thyristors are connected at both ends of the mechanical $\operatorname{switch}^{[5]} .1$ and 4,2 and 3 are the contacts of two pairs of mechanical switches respectively. Among them, 2-3 contacts have a common end, which is used as a trigger board to provide trigger current for thyristor. $\mathrm{T} 1$ and $\mathrm{T} 2$ are a pair of reverse parallel thyristor modules. Taking the action process of the mechanical contact on the $\mathrm{AB}$ branch as an example, when the $\mathrm{AB}$ branch is disconnected, the 2-3 contact is first disconnected, and the first action contact of the 2-3 contact generates a small arc at the moment of disconnection, and the arc establishes a voltage at the 1 and 4 terminals. The voltage is applied between the cathode and anode of the thyristor module and the gate and cathode of the corresponding thyristor, forming the triggering condition of the thyristor, and the operation of diodes D1 and D2 The purpose is: if there is no D1 and D2, when the current passing through the thyristor reverses in natural zero crossing after the thyristor is

*Corresponding author: jiapengfei@epri.sgcc.com.cn 
turned on, the reverse current will flow through the cathode and gate of the thyristor to the gate and cathode of another reverse parallel thyristor, so the current will not be cut off. As the PN junction $\mathrm{J} 3$ corresponding to the gate and cathode of the thyristor is very narrow, it is very easy to be broken down. After the thyristor is on, the current is transferred to the thyristor branch ${ }^{[6]}$. When the first current passes through zero, the thyristor will turn off naturally, and the maximum conduction time shall not exceed half a cycle. In the design, the half cycle time shall be considered and the mechanical error shall be controlled within $12 \mathrm{~ms}$; when the $\mathrm{AB}$ branch is closed, the 1-4 contacts shall be closed first, and the thyristor shall not be triggered, and then there shall be no arc, and then the intermediate contact 2-3 shall be closed In 2-3, the voltage between the taps between the back closed contacts forms the condition of thyristor conduction, which triggers the thyristor on and suppresses the discharge between the contacts. After the contact 2-3 is completely closed, the thyristor circuit is short circuited, and the thyristor is forced to turn off, and the current is carried by the mechanical contact.

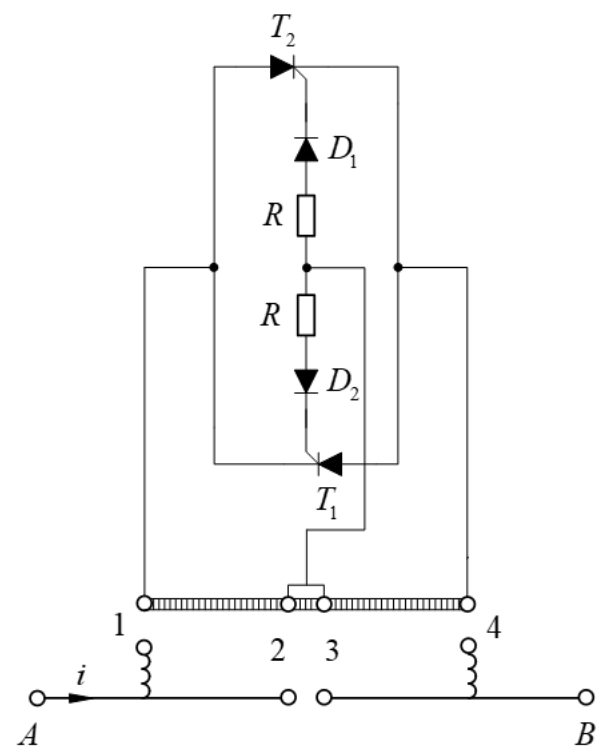

Fig. 2. Passive trigger topology of thyristor auxiliary contact

This kind of thyristor auxiliary arc extinguishing passive trigger has the following advantages: (1) the switching action does not need time control circuit, and the contact action sequence is realized by the telescopic moving contact, which does not involve the complex electromagnetic interference problem of the control circuit; (2) the thyristor circuit exits after the completion of switching, and does not carry current for a long time, which can effectively reduce the on-state loss of the thyristor and prolong the service life of the thyristor (4) even if the thyristor is out of control, the mechanical switch can still work without damaging the tap and transformer.

\section{Switching process of hybrid on load tap changer}

The switching principle of hybrid on load tap changer studied in this paper is combined with the existing $\mathrm{km}$ type tap changer principle to form the basic principle as shown in Figure 3, which is composed of three groups of thyristor modules and basic circuit of double transition resistance. The advantage of double transition resistance basic circuit is that when the load direction changes, there will be no on load tap changer fault caused by single resistance circuit switching aggravating, affecting contact life and even unable to complete normal switching. When the load direction changes, the breaking current and recovery voltage of the single resistance circuit will be twice of the rated value, which will greatly increase the switching task. The double transition resistance circuit can avoid this situation. The single resistance transition circuit is not suitable for the contact transformer with power exchange represented by phase-shifting transformer, while the double resistance transition circuit is applicable to all transformers.

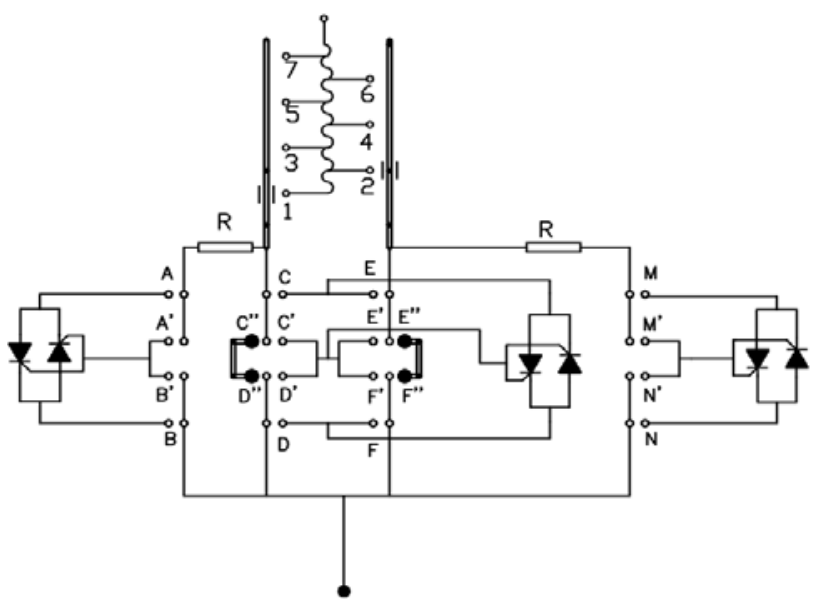

Fig. 3. Structure diagram of hybrid hybrid OLTC switch

At present, the maximum number of dynamic and static contact pairs applied to on load tap changer products is 6 , corresponding to 6 guide slots. The increase of fixed contact will increase the number of guide slots, reduce the insulation distance between contacts and affect the insulation performance. In the hybrid on load tap changer, one guide slot can be used to complete the sequential action of two moving and stationary contact pairs, which can solve the problems of large number of contact pairs and complex fracture of thyristor switch. The contact fracture is arranged in a three-dimensional way, and the timing can be adjusted by the height of telescopic spring.

Next, take the process of switching from odd to even gear as an example for in-depth analysis. On CD and EF branches, C"D" and E"F" are main contacts, other contacts are main on-off contacts, and contacts on $\mathrm{AB}$ and $\mathrm{MN}$ branches are transition contacts. In the initial state, C"D" 'is closed and its left main contact C"D" is closed, and the $\mathrm{CD}$ branch is connected. Then the main contact $C^{\prime \prime} \mathrm{D}^{\prime \prime}$ is opened and $\mathrm{AB}$ is closed. After $10-12 \mathrm{~ms}$, $\mathrm{A}^{\prime} \mathrm{B}^{\prime}$ is closed. After $2 \mathrm{~ms}, \mathrm{C}^{\prime \prime} \mathrm{D} "$ is opened. At the moment of opening, an arc is generated to trigger the middle thyristor circuit. The current is conducted by the 
CD circuit through the thyristor for about $10 \mathrm{~ms}$ (depending on the action phase). When the current passes through zero, the thyristor will turn off naturally, and the current will be turned off by AB Branch conduction. After $2 \mathrm{~ms}, \mathrm{CD}$ is opened, about $3-5 \mathrm{~ms}$ later, $\mathrm{MN}$ is closed. About 6-8ms later, the right thyristor circuit is triggered during the closing process of $\mathrm{M}^{\prime} \mathrm{N}^{\prime}$, and a bridge is formed. After about $2-3 \mathrm{~ms}$, the $\mathrm{M}^{\prime} \mathrm{N}^{\prime}$ is completely closed, the current is conducted through $\mathrm{M}^{\prime} \mathrm{N}^{\prime}$, and the thyristor circuit is short circuited. After about $4 \mathrm{~ms}, \mathrm{~A}^{\prime} \mathrm{B}^{\prime}$ is opened, and an arc is generated at the moment of opening to trigger the thyristor circuit on the left side. After about $8-10 \mathrm{~ms}$, the thyristor will automatically extinguish when the current is zero. After about 2-3ms, AB opens, about 3-5ms after AB opens, EF closes. About $10 \mathrm{~ms}$ later, $\mathrm{E}^{\prime} \mathrm{F}^{\prime}$ triggered the middle thyristor circuit during the closing process. After about 2-3ms, the $E^{\prime} F^{\prime}$ is completely closed and the thyristor circuit is short circuited. $\mathrm{M}^{\prime} \mathrm{N}^{\prime}$ is opened, $\mathrm{MN}$ is opened after about $8-12 \mathrm{~ms}$, and then the right main contact of $E^{\prime} F^{\prime}$ is closed. At this time, a complete switching process is completed.

\section{Switching process of thyristor assisted arc extinguishing hybrid OLTC}

Table 1 shows the one-time switching process of on load tap changer from odd position to even position. From this table, it can be clearly seen that the thyristor will be triggered four times in a switching process of hybrid on load tap changer, and two times are triggered when opening and closing, and the arc voltage between contacts when the contact head is open and the action sequence of telescopic moving contact is thyristor The key of power trigger and turn off.

Table 1. Switching process from odd to even of hybrid on load tap changer

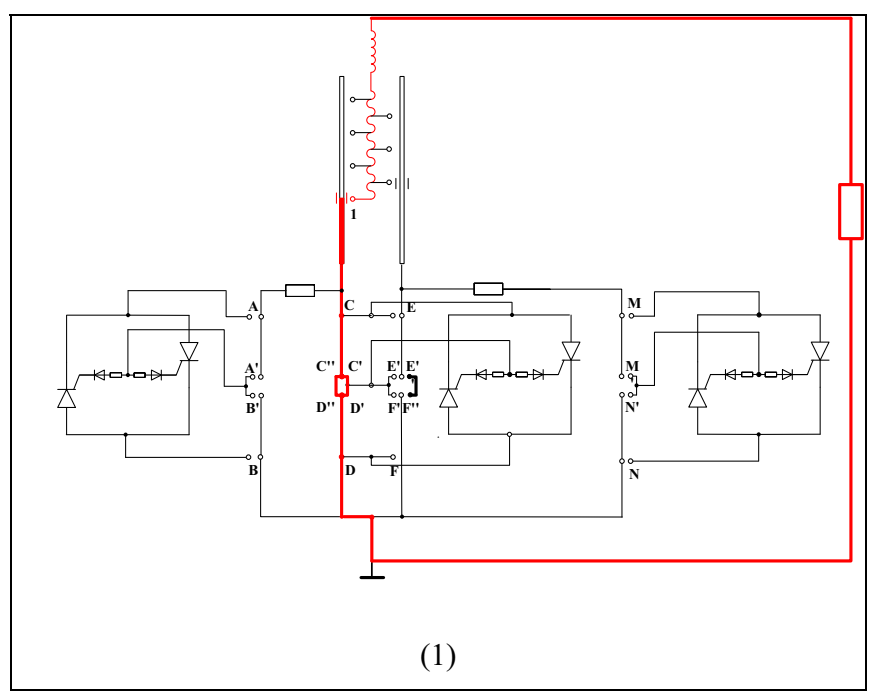

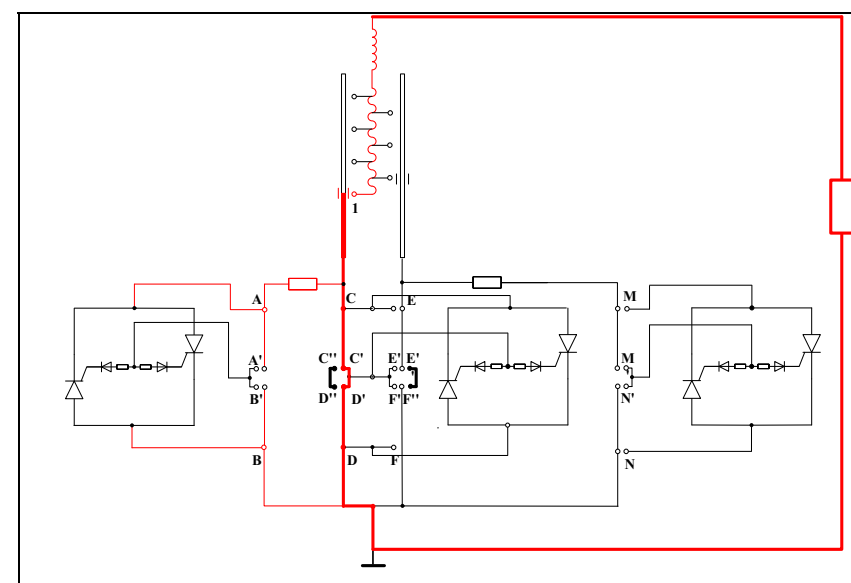

(2)

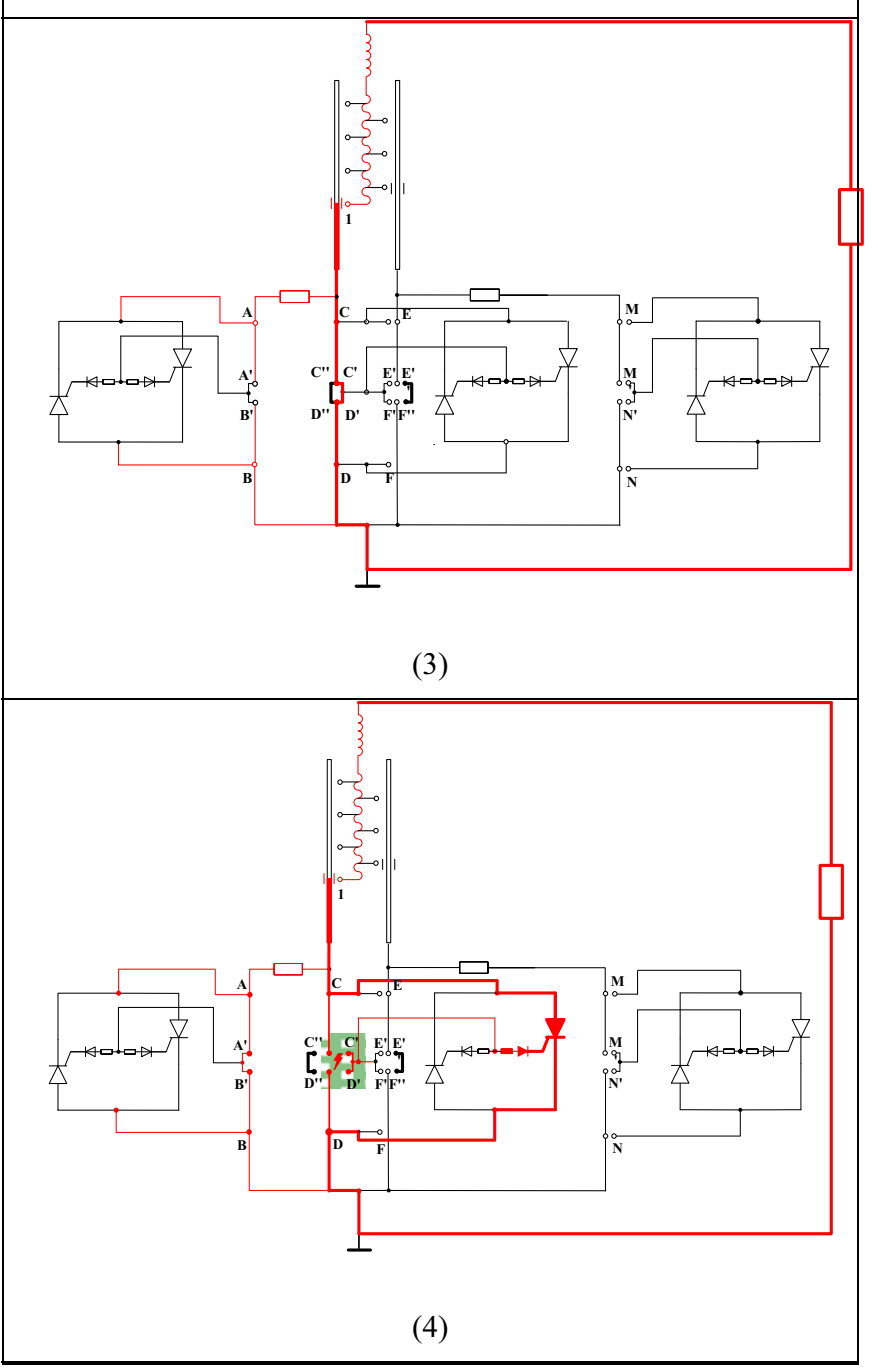




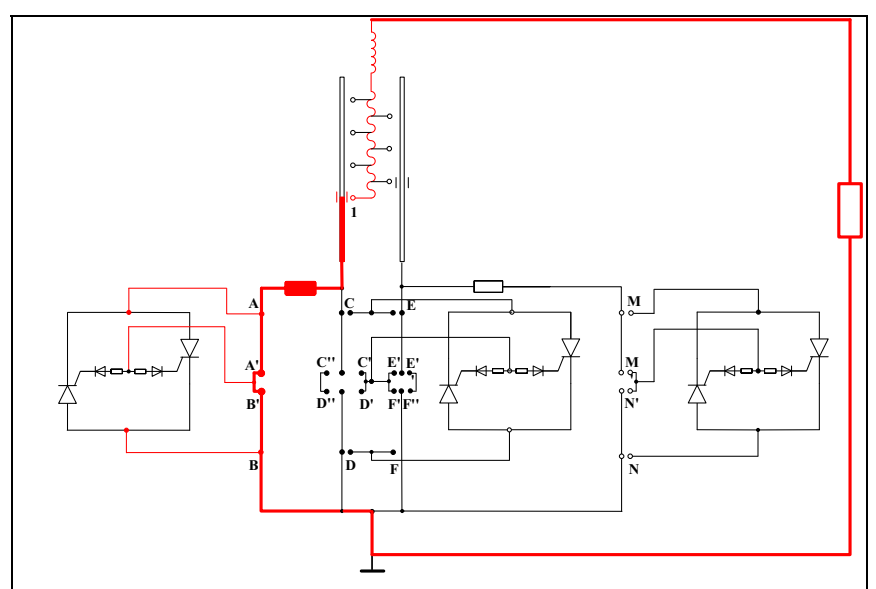

(5)

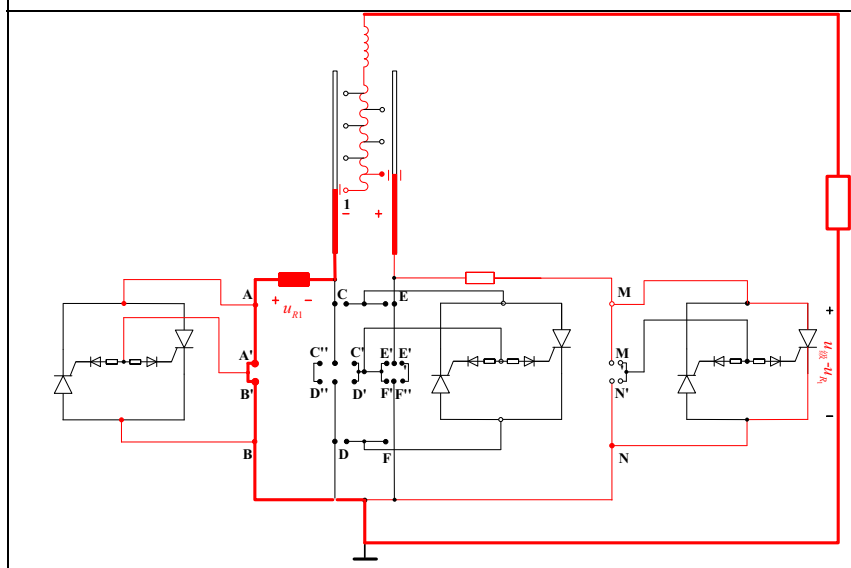

(6)

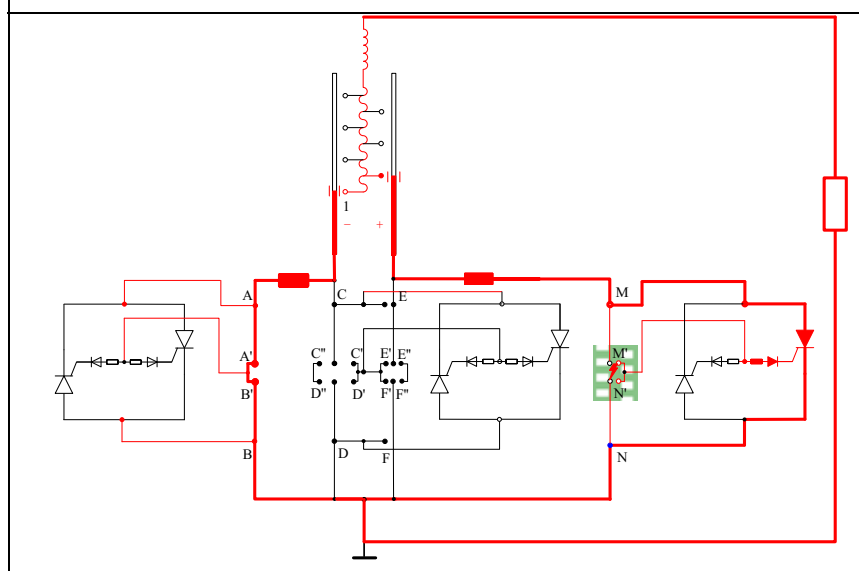

(7)

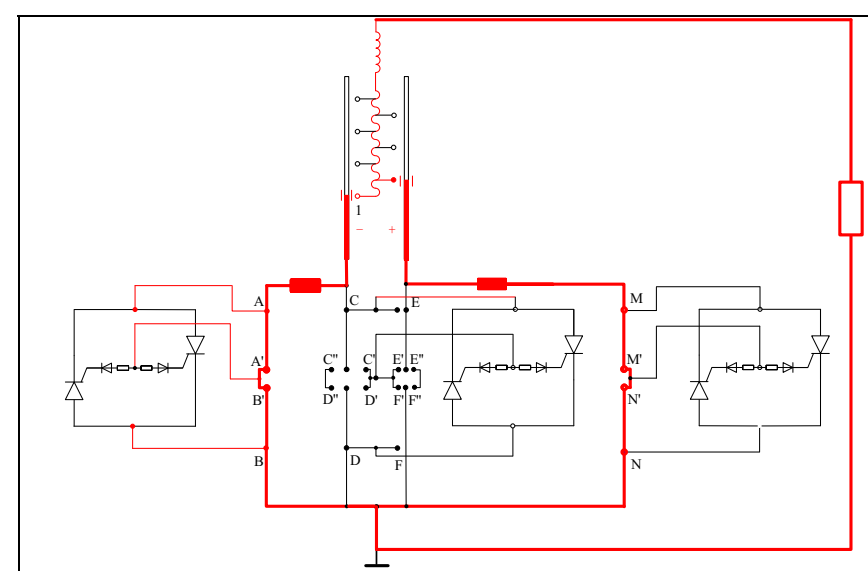

(8)

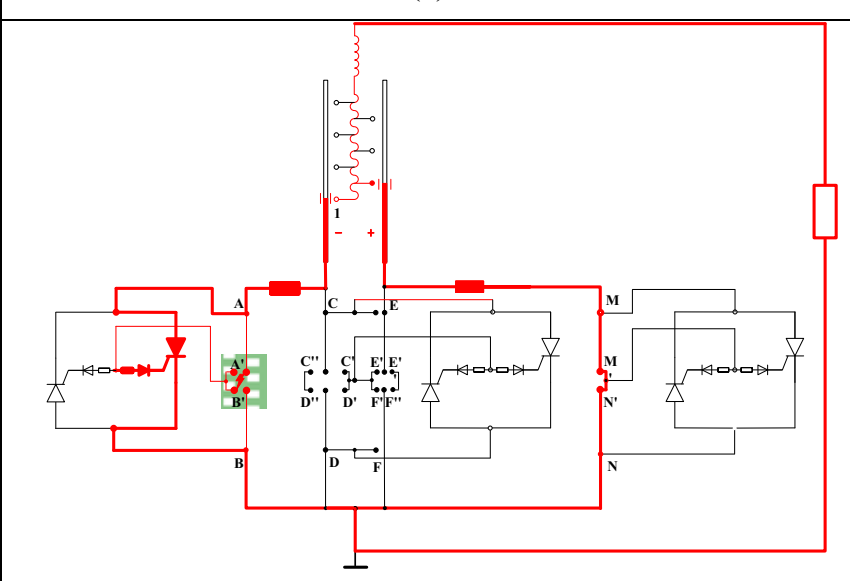

(9)

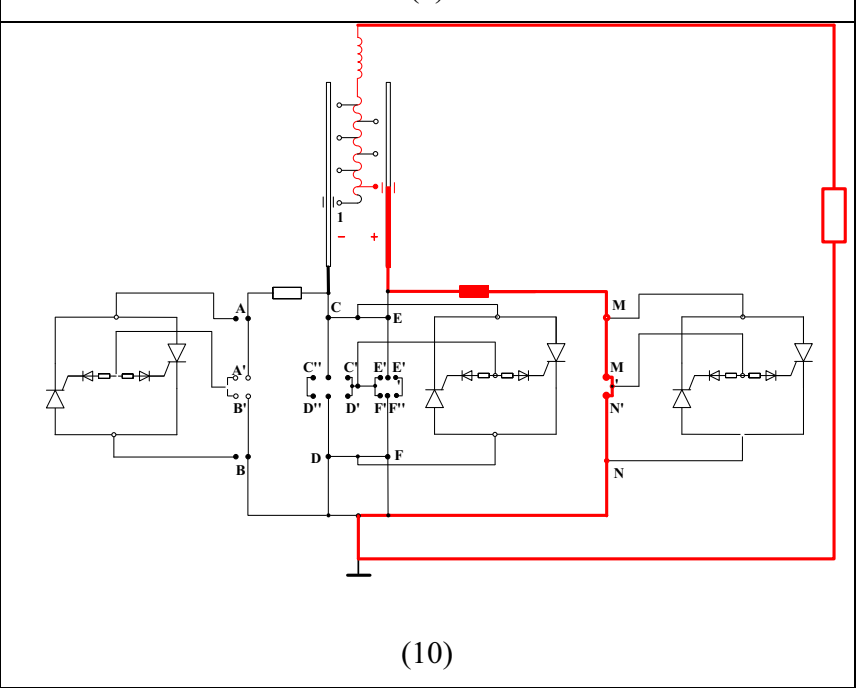




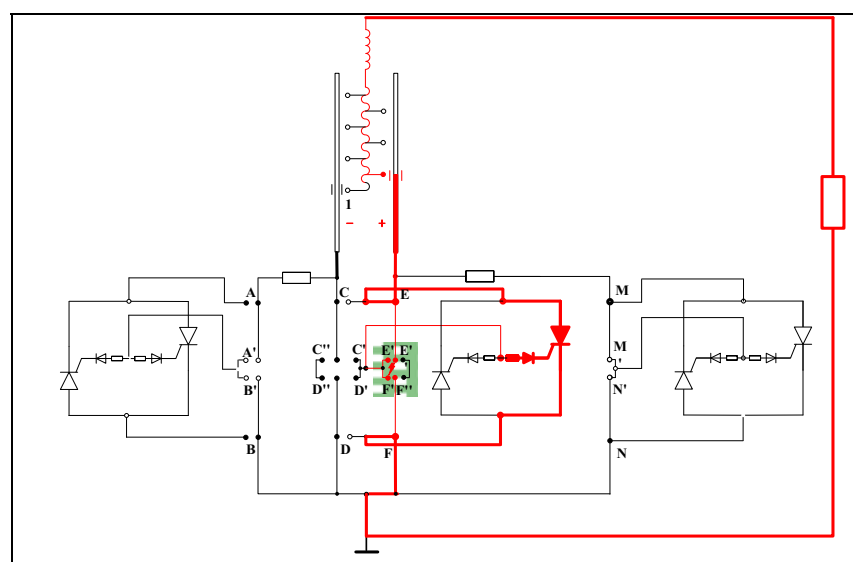

(11)

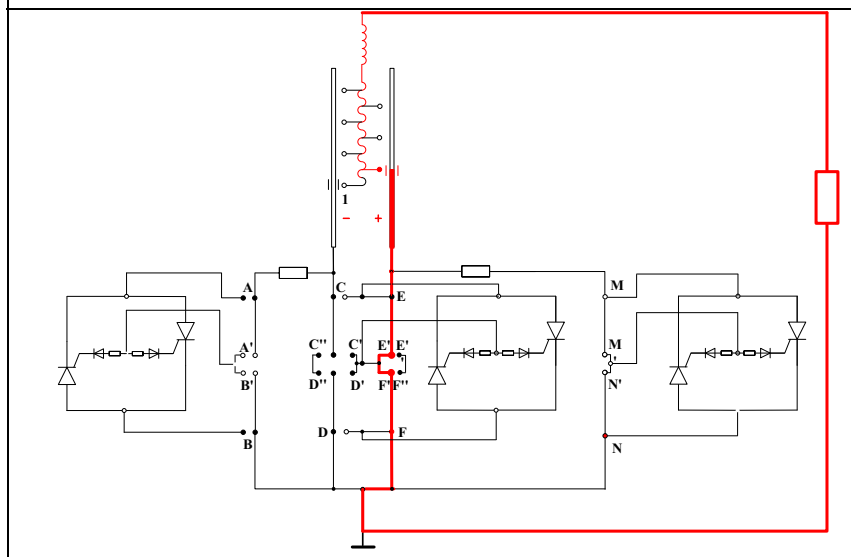

(12)

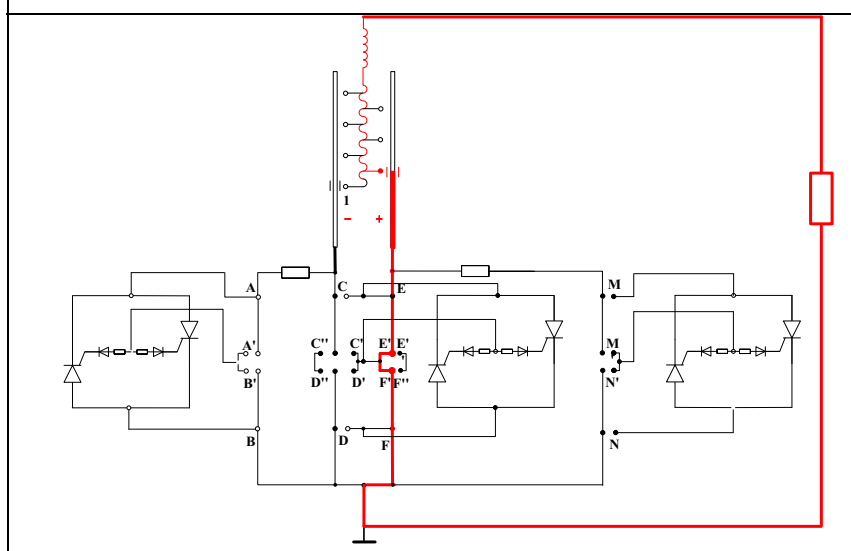

(13)

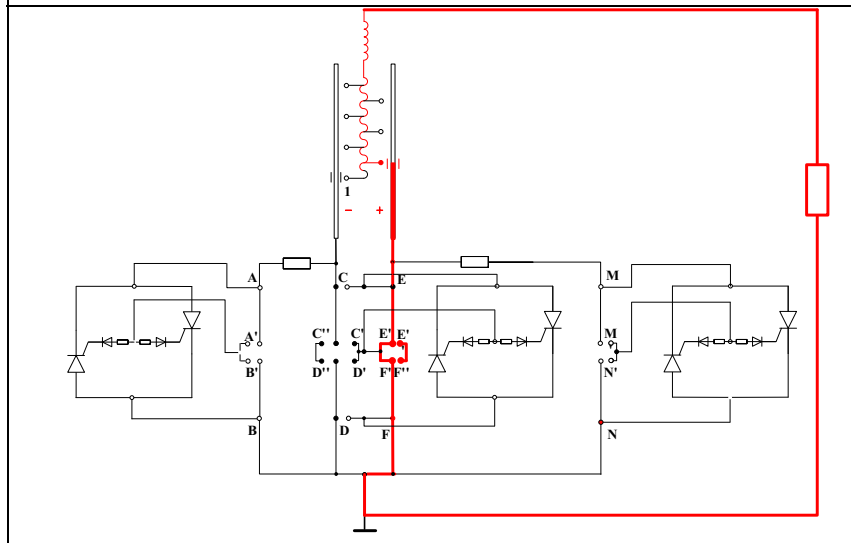

(14)

\section{Conclusion}

Compared with mechanical OLTC and power electronic OLTC, hybrid OLTC has the following characteristics:

(1) It uses power electronic devices to assist mechanical contact switching. The transition branch can be conducted only in the micro arc stage during the switching process, which greatly reduces the deterioration of transformer insulating oil performance in the switching process, reduces the times of oil filtering and oil changing, and increases the service life of the switch.

(2) After switching, the power electronic devices exit the current carrying circuit and carry the current by mechanical contacts, which reduces the loss caused by the long-term conduction of power electronic devices, avoids the low reliability of the switch caused by the damage of the power electronic devices, and prolongs the service life of the on load tap changer.

(3) The hybrid on load tap changer also has some shortcomings, which can effectively solve the problem of arc generated in the switching process of mechanical on load tap changer, but it does not solve the problem of slow response speed of mechanical on load tap changer. Compared with power electronic on load tap changer, the switching speed is slower.

\section{References}

1. ROBERTS, M.E, and ASHMAN, W.G. A thyristor assisted mechanical on-load tap changer. Proceeding of IEE Conference on Power thyristors and their application, 1969: 185-192.

2. Harlow JH, Stich F A. An arcless approach to stepvoltage regulation[J]. IEEE Transactions on power apparatus and systems, 1982, 101(7) : 2096-2102.

3. D. Gao. 2002 "A novel thristor assited diberter switch for a solid-state tap changer ", Transmission and Distribution Conference and Exhibition 2002: Asia Pacific. IEEE/PES, Vol. 1, pages 297-300.

4. Gómez-Expósito, Bachiller-Sloer. A lab setup illustrating thyristor-assisted under-load tap changers[J]. IEEE Transaction on Power Systems, 2010, 25(3) : 1204-1210.

5. Monroy-Berjillos D, Gomez-Exposito A, BachillerSoler A. A lab setup illustrating thyristor-assisted under-load tap changers [J]. IEEE Transactions on Power Systems, 2010,25(3) : 1203-1210.

6. IEC 60214. 1 2014, Tap-changers Part 1: Performance requirements and test methods[S]. Switzerland: International Electrotechnical Commission, 2014 